\section{Synthese von Puryl-(6)-alanin *}

C. Woenckhaus und A. Stock

Institut für Biochemie im Institut für Organische Chemie der Universität Frankfurt a. M.

(Z. Naturforschg. 20 b, 400 [1965]; eingegangen am 27. Januar 1965)

Vor einiger Zeit berichteten Tschaman und Mitarbb. ${ }^{1}$ über Synthesen von 2-Chlor-9-methyl-puryl-(6)-alanin und 9-Methyl-puryl-(6)-alanin. Puryl-(6)-alanin wird von uns durch Behandeln der Puryl-(6)-acrylsäure ${ }^{2}$ mit Hexamethyldisilazan hergestellt. Bei diesem Umsatz wird das Purin in Stellung 9 mit dem Trimethylsilylrest besetzt ${ }^{3}$ und vermutlich die Säure verestert. Die Doppelbindung des Acrylsäurerestes ist befähigt, Hexamethyldisilazan anzulagern. Durch saure Hydrolyse gelingt die Abspaltung aller Silylreste.

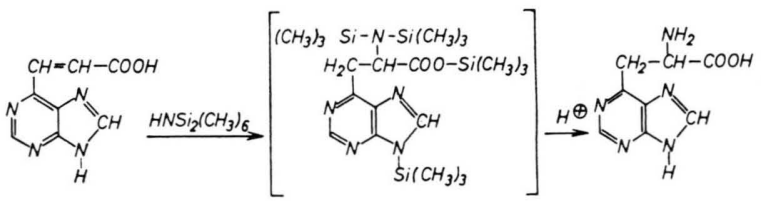

Durch Chromatographie an einer Dowex-50- $\mathrm{H}^{\oplus}$-Säule wird Puryl-(6)-alanin gereinigt. Die Verbindung kristallisiert in Nadeln aus Wasser. Sie ist an der Luft stabil, gibt aber beim Erwärmen im Vakuum Ammoniak ab. Diese Reaktion läßt sich durch Messen des UV-Spektrums verfolgen. Puryl-(6)-alanin absorbiert

* Úber die mögliche Bedeutung des Puryl-(6)-alanins in der Tumorforschung s. H. Letrré, Progress of exp. tumor res. Bd. I, S. 329, New York 1960.

1 E. C. Tschaman u. E. C. Golobtschinskaj, Zh. Obshch. Khim. 33,3342 [1963]. bei $262 \mathrm{~m} \mu$ die Puryl-(6)-acrylsäure bei $305 \mathrm{~m} \mu$. Der leichte Übergang zur Puryl-(6) -acrylsäure wurde auch bei der Puryl-(6) -milchsäure ${ }^{2}$ beobachtet. Ninhydrin zeigt mit Puryl-(6)-alanin eine orange Farbreaktion.

\section{Ausführung der Synthese}

$250 \mathrm{mg}$ Puryl-(6) -acrylsäure werden mit $2 \mathrm{~cm}^{3}$ Hexamethyldisilazan 14 Stdn. unter Rückfluß gekocht. Anschließend wird das Reaktionsgemisch in $200 \mathrm{~cm}^{3} 2-n$. Salzsäure hydrolysiert. Nach dem Eindampfen bei $40^{\circ}$ i. Vak. wird der Rückstand in wenig Wasser gelöst, auf eine Dowex-50- $\mathrm{H}^{\oplus}$-Säule $(200-400 \mathrm{mesh}, 20 \cdot 2 \mathrm{~cm})$ gegeben und mit Salzsäure eluiert. Die Aminosäure erschien nach Aufgabe 2-n. Salzsäure im Eluat. Das Eluat wurde i. Vak. zur Trockene eingedampft, der Rückstand in $3 \mathrm{~cm}^{3}$ Wasser gelöst und mit 2-n. Natronlauge auf $p_{\mathrm{H}} 8$ eingestellt. Nach Filtration wird mit Essigsäure auf $p_{\mathrm{H}} 4$ angesäuert. Puryl-(6)-alanin kristallisiert nach Zugabe von $10 \mathrm{~cm}^{3}$ Äthanol. Ausbeute $157 \mathrm{mg}(30 \%)$. Schmp. Zersetzung ab $165^{\circ}$, kein Schmelzen. Zur Reinigung wird die Aminosäure in Wasser suspendiert, mit verdünnter Natronlauge gelöst und mit Essigsäure wieder $p_{\mathrm{H}} 4$ eingestellt. Anschließend wird die Lösung angeimpft.

$\mathrm{C}_{8} \mathrm{H}_{9} \mathrm{~N}_{5} \mathrm{O}_{2} \cdot \mathrm{H}_{2} \mathrm{O} \quad(225,22)$

$\begin{array}{llllll}\text { Ber. } & \text { C } 42,66 & \text { H } & 4,92 & \text { N } 31,10 \text {, } \\ \text { Gef. } & \text { C } 42,59 & \text { H } & 5,04 & \text { N } 30,06 .\end{array}$

Eine unter Atmosphärendruck getrocknete Probe zeigte: $40,69 \%$ C, $29,22 \% \mathrm{~N}$. C : $\mathrm{N}=8: 4,83$, ber. $\mathrm{C}: \mathrm{N}=8: 5$.

2 H. Lettré u. C. Woenckhaus, Liebigs Ann. Chem. 649, 131 [1961].

3 H. Bräuniger u. A. Koine, Arch. Pharmaz. Ber. dtsch. pharmaz. Ges. 269, 668 [1963].

\section{Reinigung des Friend-Leukämievirus im K-Tartrat-Gradienten}

T. ODAKA * und K. KöHLER

Max-Planck-Institut für Virusforschung, Abteilung für physikalische Biologie, Tübingen

(Z. Naturforschg. 20 b, 400-401 [1965]; eingeg. am 3. November 1964)

Das Friend-Leukämievirus konnte bisher nicht befriedigend gereinigt und angereichert werden. Vor allem geht durch Zentrifugation infektiöser Lösungen auf dem Boden des Röhrchens ein großer Teil der im Tierversuch geschätzten Infektiosität verloren. Da dieses Virus auch im Blut vorkommt ${ }^{1}$, wurde verusucht, es daraus auf möglichst schonende Art anzureichern. Im hiesigen Laboratorium wurde bereits das Adenovirus ${ }^{2}$ aus Zellextrakt auf eine Schicht CsCl-Lösung höherer

* Stipendiat der Humboldt-Stiftung.

1 T. ODAKA, Gan no Rynsho 8, 260 [1962].

2 K. Köhler, Z. Naturforschg. 17 b, 544 [1962].
Dichte statt auf dem Boden des Röhrchens zentrifugiert, nachdem sich diese Methode auch beim RousSarcoma-Virus ${ }^{3}$ bewährt hatte. Wir benutzten daher zunächst CsCl, fanden jedoch, daß die Aktivität des Virus nach 16-stdg. Zentrifugation verloren ging. Im folgenden wird nun die erfolgreiche Reinigung und Anreicherung des Virus im K-Tartrat ${ }^{4}$ beschrieben.

$10 \mathrm{ml}$ Serum an Leukämie erkrankter Mäuse wurden auf $20 \mathrm{ml}$ einer K-Tartrat-Lösung mit einem Konzentrations-Gradienten von $10-30 \%$ geschichtet und in der Ultrazentrifuge (Spinco, Rotor SW 25) bei 22500 $\mathrm{U} / \mathrm{min}$ nur 2 Stdn. lang zentrifugiert. Das obere Drittel des Röhrchens enthält nach der Zentrifugation meist Hämoglobin, darunter wird eine Bande stark lichtstreuenden Materials angereichert. Die Dichte des Tartrats im Bereich der Bande liegt zwischen 1,13 und

${ }^{3}$ L. V. Crawford, Virology 12, 143 [1960].

4 J. F. McCrea, R. S. Epstein u. W. H. Barry, Nature [London] 189, 220 [1961] ; C. J. Pfau u. J. F. McCrea, Virology 21, 425 [1963]. 